\title{
Postoperative complications after procedure for prolapsed hemorrhoids (PPH) and stapled transanal rectal resection (STARR) procedures
}

\author{
M. Pescatori • G. Gagliardi
}

Received: 12 December 2007 / Accepted: 2 February 2008

\begin{abstract}
Procedure for prolapsing hemorrhoids (PPH) and stapled transanal rectal resection for obstructed defecation (STARR) carry low postoperative pain, but may be followed by unusual and severe postoperative complications. This review deals with the pathogenesis, prevention and treatment of adverse events that may occasionally be life threatening. PPH and STARR carry the expected morbidity following anorectal surgery, such as bleeding, strictures and fecal incontinence. Complications that are particular to these stapled procedures are rectovaginal fistula, chronic proctalgia, total rectal obliteration, rectal wall hematoma and perforation with pelvic sepsis often
\end{abstract}

${ }^{1}$ Presented in part at the Cleveland Clinic Florida's 19th Annual International Colorectal Disease Symposium, 14-16 February 2008, Fort Lauderdale, USA requiring a diverting stoma. A higher complication rate and worse results are expected after PPH for fourthdegree piles. Enterocele and anismus are contraindications to PPH and STARR and both operations should be used with caution in patients with weak sphincters. In conclusion, complications after PPH and STARR are not infrequent and may be difficult to manage. However, if performed in selected cases by skilled specialists aware of the risks and associated diseases, some complications may be prevented.

Keywords PPH, STARR · Stapled hemorrhoidopexy · Stapled rectal resection - Postoperative complications . Hemorrhoids · Obstructed defecation

\section{Introduction}

Stapled transanal mucosectomy, first experimented at our unit [1], aims to treating rectal internal mucosal prolapse and obstructed defecation. The technique was later proposed by Longo [2] for the treatment of hemorrhoids. Subsequently called stapled hemorrhoidopexy or procedure for prolapsed hemorrhoids (PPH), the technique gained a wide popularity due to the low postoperative pain $[3,4]$. Almost all studies, with a few exceptions [5, $6]$, also found an early return to work.

Recently, a systematic review [7] and a Cochrane meta-analysis [8] showed that the recurrence rate after PPH is higher than that after manual hemorrhoidectomy (5.7\% vs. $1 \%$ at one year and $8.5 \%$ vs. $1.5 \%$ in the long term) $[7,8]$. Both the systematic review as well as the practice parameters of the American Society of Colon and Rectal Surgeons [9] mention the rare occurrence of potentially devastating complications after PPH.
G. Gagliardi

Pineta Grande Hospital

Castel Volturno, Caserta, Italy 
Nevertheless, the most recent systematic review on PPH, which included more patients, showed no difference in symptomatic recurrence rate and attributed all major complications to surgical errors [10].

Rectal wall resection with a circular stapler was the basis for the development of the stapled transanal rectal resection (STARR) procedure. This procedure consists of a double transanal rectal resection and is aimed at correcting the anatomical disorder of the rectum in patients with rectocele and rectal intussusception causing obstructed defecation $[11,12]$. As we do not know the exact significance of these anatomical abnormalities, it is uncertain that by correcting the anatomy we can restore normal function [13]. This procedure has quickly gained popularity among surgeons, while failures and complications have only recently been reported $[14,15]$.

We reviewed the adverse events after $\mathrm{PPH}$ and STARR procedures and the management of these postoperative complications, with the aims of decreasing postoperative morbidity and improving patients' outcomes after these novel procedures.

\section{Materials and methods}

Meta-analyses, prospective trials, case series, case reports and abstracts reporting postoperative complications after PPH and STARR were retrieved from all major electronic databases (Medline, Embase, Cochrane Central Register of Controlled Trials) up to November 2007. In addition, adverse events requiring intervention using the
PPH01 or PPH03 staplers (Ethicon Endo-Surgery, Cincinnati, USA) reported to the U.S. Food and Drug Administration (FDA) Center for Devices and Radiologic Health (CDRH) [16] were examined (Table 1).

\section{Complications following PPH}

One multicenter study reported that $36.4 \%$ of patients had at least one adverse event following PPH [17]. A systematic review found that $20.2 \%$ had postoperative complications [10]. In another study in which PPH was done as day case procedure, $12.7 \%$ of patients required readmission on the day of surgery, mostly due to bleeding, pain and urinary retention [18]. The recurrence rate was high when PPH is used to treat for fourth-degree hemorrhoids [19]. Apart from bleeding, strictures and fissures, which are equally reported after manual hemorrhoidectomy [20], unusual complications (e.g. rectal obliteration [21], rectal perforation [22, 23] with retropneumoperitoneum [23] and pneumomediastinum $[23,24])$ as well as chronic pain [5] have been reported following PPH. The occurrence of such complications originated a discussion at the Italian Parliament in 2005 on the high costs and the potential abuse of the technique [25].

Reintervention rates of $6.4 \%$ for complications at one month and $11 \%$ for complications and failures at one year have been reported following PPH in two retrospective studies [26, 27], but in a recent prospective study, Fueglistaler et al. [28] reported a lower reintervention rate (5\% at two years). The reintervention rate after man-

Table 1 Complications requiring intervention occurring with PPH01 or PPH03 staplers as reported to the FDA [16]

\begin{tabular}{|c|c|c|c|c|c|c|c|c|c|c|}
\hline & \multirow{3}{*}{$\mathrm{n}$. } & \multicolumn{4}{|c|}{ Cause } & \multicolumn{5}{|c|}{ Intervention } \\
\hline & & \multirow[t]{2}{*}{$\begin{array}{l}\text { Technical } \\
\text { error }\end{array}$} & \multirow[t]{2}{*}{$\begin{array}{l}\text { Stapler } \\
\text { failure }\end{array}$} & \multirow[t]{2}{*}{$\begin{array}{l}\text { No problem } \\
\text { noted }\end{array}$} & \multirow[t]{2}{*}{ Unknown } & \multirow{2}{*}{$\begin{array}{l}\text { Transanal } \\
\text { repair } \\
\text { only }\end{array}$} & \multicolumn{2}{|c|}{$\begin{array}{r}\text { Abdominal } \\
\text { surgery }\end{array}$} & \multirow[t]{2}{*}{$\begin{array}{l}\text { Non } \\
\text { surgical }\end{array}$} & \multirow[t]{2}{*}{ Unknown } \\
\hline & & & & & & & with stoma & without stoma & & \\
\hline \multicolumn{11}{|l|}{ Complication } \\
\hline Rectal wall defect ${ }^{* ¥}$ & 40 & 1 & 28 & 11 & & 18 & 14 & 6 & & 2 \\
\hline Rectal obliteration & 3 & & & 3 & & 1 & 2 & & & \\
\hline Rectovaginal fistula & 2 & 1 & & & 1 & & 1 & & & 1 \\
\hline $\begin{array}{l}\text { Rectal injury }{ }^{\neq} \\
\text {causing bleeding }\end{array}$ & 75 & & 38 & 37 & & 62 & 1 & & 4 & 8 \\
\hline $\begin{array}{l}\text { Impossible to } \\
\text { remove stapler }\end{array}$ & 25 & & 22 & & 3 & 24 & & & & 1 \\
\hline Cut but did not staple & 18 & & 18 & & & 16 & & & & 2 \\
\hline Other & 9 & & 6 & & 3 & 6 & & & 1 & 2 \\
\hline Total & 172 & 2 & 112 & 51 & 7 & 127 & 18 & 6 & 5 & 16 \\
\hline
\end{tabular}

\footnotetext{
* one patient in this group had both rectal obliteration and rectal wall defect

$¥$ in 2 cases surgery was for rectocele

$\neq$ in 6 cases surgery was for rectocele
} 
ual hemorrhoidectomy has been reported to be $1.7 \%$ [29]. The need for further surgery showed a significant trend in favor of manual hemorrhoidectomy in a meta-analysis by Jayaraman et al. [8], whereas another review reported a similar early reintervention rate after the two procedures [10].

\section{Rectal bleeding}

Rates of rectal bleeding after PPH for second-, third- and fourth-degree piles without thrombosis range between $1 \%$ and $11 \%[10,17,30]$. Rectal bleeding after PPH required readmission within two weeks in $5.6 \%$ of over 3000 cases operated in Singapore [31]. Only $1.8 \%$ of these cases required re-treatment and $0.4 \%$ required a second anesthesia for surgical hemostasis, as the bleeding was stopped by endoanal adrenaline injection in most cases [32]. Surgical reintervention was needed more frequently $(1.5 \%)$ in another series [33]. Bleeding tends to occur either immediately after surgery or between the fourth and tenth days after surgery [33] and may occasionally cause a hematoma which may require a late rectotomy to be evacuated [34]. According to a meta-analysis that analyzed 15 prospective randomized trials, the hemorrhoidopexy:hemorrhoidectomy ratio of postoperative rectal bleeding was 2.3:1 [7]. Bleeding is more likely to occur after PPH for fourth-degree hemorrhoids $(11 \%)$ [30, 35], for anorectal varices $(25 \%)$, and for thrombosed hemorrhoids (67\%) [36]. According to a retrospective study, 34\% of patients reoperated after PPH had postoperative bleeding [27]. One patient underwent a colectomy after severe and recurrent bleeding following stapled hemorrhoidopexy: the source of bleeding was not promptly identified as the hemorrhage was intermittent, so the colectomy was carried out for a suspected colonic lesion; eventually the bleeding area was detected at the PPH staple line [37].

Four factors may help to minimize the risk of bleeding: manual overstitching of the staple line; use of the PPH03 gun, which has a smaller staple closure and is more hemostatic; tightening the gun to the absolute limit; and use of a postoperative endoanal sponge [38-40]. The bleeding rate decreased from $12.9 \%$ to $4.4 \%$ with the increasing experience of the surgeon in performing PPH [26].

The relatively high rate of postoperative bleeding implies that the vascular supply to the hemorrhoids is not interrupted by PPH as hypothesized. Instead, Aigner et al. demonstrated with anatomical dissections that neither PPH nor Doppler ligation completely interrupt the superior rectal artery branches, and of course there is still the vascular supply from below [41].
Acute pain

Early postoperative pain is reported to be lower after PPH than after manual hemorrhoidectomy [3, 4, 34, 42-45]. Pain may be induced by a low anastomosis at the level of the sensitive epithelium, if the purse string is carried out too close to the dentate line, either in the lower rectum or in the upper anal canal [46]. In a large series of over 3500 patients pain was so severe as to require readmission in $1.6 \%$ of the cases [32].

\section{Chronic pain}

Severe chronic proctalgia after PPH is rarely reported. The incidence of chronic pain ranges from $1.6 \%$ to $31 \%$ in the studies reporting this complication $[5,17,19,20$, 47-51]. The two studies that better characterized chronic pain reported it as either post-defecatory [5] or accompanied by urgency [48]. In the study by Cheetham et al. [48] symptoms developed immediately after surgery in 2 patients and after 10 days to 5 months in another 3 patients, while in the study of Thaha et al. [5] pain developed at a median of 3 weeks (range, 1-5) after surgery.

Chronic pain has been related to smooth muscle incorporation in the doughnut although it may be present without muscle incorporation [48]. Chronic pain has also been attributed to persistent hemorrhoidal disease [7, 27, 49], sphincter spasm, rectal spasm or high anal resting pressures $[5,28,57,51]$, suture dehiscence [7, 27, 49, 52, 53], anal fissure [27], anorectal sepsis [27] or retained staples [27, 54]. Chronic pain may occur more frequently in males [5, 48, 55]. Comparing long-term results of PPH and Milligan-Morgan procedure for fourth-degree piles, Mattana et al. [56] found that $8 \%$ of patients who had stapled hemorrhoidopexy complained of spontaneous pain or pain during defecation vs. $0 \%$ of patients who underwent the MilliganMorgan procedure, although this difference was not statistically significant.

Post-evacuatory pain may respond to oral nifedipine [5]. Chronic proctalgia may otherwise be a severe problem which is difficult to manage, and represents the most frequent indication for reintervention after $\mathrm{PPH}$ (44\% of the reoperated patients [27]). A novel procedure called "agrapphectomy" (from French agrapphes = staples) involving the excision of the staple line and the manual refashioning of the anastomosis, has been advocated as effective by Wunderlich et al. [54]. A more conservative approach using transanal electrostimulation or transanal injections of steroids and local anesthetic may be also attempted [57]. 
Bleeding rectal polyps and retained staples causing bleeding

Bleeding polyps represent a granulomatous foreign body reaction to retained staples [58-61], and have been shown to occur in $11 \%$ of patients after PPH [58]. This is a late complication occurring between postoperative week 6 and 16 [58]. Retained staples, besides causing bleeding, may also be a cause of chronic pain [27, 54]. Both bleeding and pain may respond to transanal staple removal [27, $54,58]$, which is one of the most frequent reinterventions after PPH [27].

Skin tags, thrombosed external piles, fecal impaction, proctitis, anal fissure, stricture, local abscess and fistula

Skin tags are more frequent after stapled hemorrhoidectomy $[8,10]$. Thrombosis is unlikely after excisional hemorrhoidectomy but may occur in up to $5.9 \%$ of cases after PPH if an external component and prolapse are present [62]. Fecal impaction requiring enema occurred in $6.6 \%$ of 300 patients [63] and constipation was reported in $6.5 \%$ of 77 patients [17]. Chronic proctitis, possibly secondary to ischemia, has been reported in three cases [27, 63, 64].

Fissures occur rarely $(0.2 \%$ according to Slawik et al. [65]) and may be due to the trauma of a forceful insertion of the stapler into a tight anus in young males. There was no discernible difference between PPH and manual hemorrhoidectomy in the incidence of postoperative anal fissure in recent reviews $[8,66]$.

Although no meta-analysis showed differences in postoperative anal stenosis, a prospective randomized trial of PPH vs. Ferguson hemorrhoidectomy reported anal strictures in $2.6 \%$ vs. $0 \%$, respectively [17]. Incidence of postoperative stenosis was $8.8 \%$ and $1.6 \%$ in two retrospective series $[31,49]$. Most of the cases responded to anal dilatation [49] while surgery was required in $1.4 \%$ of patients [32]. Most of the strictures occurred in the early postoperative period in a series published by surgeons who perform the purse-string lower than usual, excising most of the pile and therefore taking more risks in terms of potential fibrosis of the upper anal canal [33]. Dilatation after stricture was reported to result in a perforation causing retropneumoperitoneum [67]. Rectal stricture, possibly related to pre-PPH sclerosing injection and accompained by severe anal pain, occurred in $2.5 \%$ of patients in a Chinese series [68]. Stricture may also respond to gentle dilatation with a Foley catheter under tension [69].

Local abscess or fistula occur with a frequency of $0 \%-3 \%[17,19,63,70,71]$. Reporting on a series of patients who had surgery for co-existing anal lesions at the time of $\mathrm{PPH} \mathrm{Ng}$ et al. describe a severe perianal abscess requiring reintervention following $\mathrm{PPH}$ and fistulectomy [72]. A curious case of anal sepsis secondary to the passage of a chicken bone through a dehisced staple line has recently been reported [73].

\section{Rectovaginal fistula}

Rectovaginal fistula has been reported to be an occasional complication after PPH [74] and occurred in 1 case $(0.2 \%)$ in a series of 449 patients [33]. One of the 2 cases reported to the FDA required stoma formation (Table 1). Fistula is more likely to be due to local ischemia rather than to a direct trauma and usually becomes evident days after the operation. A careful vaginal inspection during the procedure helps to minimize the risk of such harmful event, which may require a reoperation. A simple trick aimed at preventing a lesion to the vagina, and also to the prolapsed pouch of Douglas, is to inject saline under the anterior aspect of the rectum, below the mucosal layer; this increases the distance with the vagina and reduces the risk of taking a bite of vagina while placing the purse string and firing the gun [75].

\section{Complete rectal obliteration}

This complication has been reported after PPH [76-78]. It may be due to erroneous placement of a purse string or to firing the stapler outside the purse string in a blind pocket from redundant rectal mucosa. A careful deep digital exploration of the rectum after the procedure should alert the surgeon to the occurrence of this complication, which may require either fluoroscopic insertion of a guidewire and subsequent dilatation or transanal release of the strictured area and subsequent refashioning of the anastomosis. Four other cases of rectal obliteration are reported on the FDA website [16], 3 of them required a colostomy and one resulted in the patient's death (Table 1).

\section{Rectal pocket}

A partial slippage of the purse string may cause a pathological pocket in the lower rectum, resembling a diverticulum or an intramural fistula. This may lead to an intermittent collection of fecalith with subsequent inflammation and local sepsis mimicking a perirectal or perianal abscess and requiring a lay-open of the pocket. This was the case in 5 patients observed at our institution [79]. One of these patients, a man, with an anterior rectal pocket following repeat $\mathrm{PPH}$, developed proctalgia and chronic pro- 
statitis, possibily due to bacterial translocation. The incidence of this complication is $2.5 \%$ [79] and the lay-open of the pocket is effective in most cases.

\section{Rectal dysplasia or adenocarcinoma}

This is a rare but possible event, due either to a misdiagnosed hemorrhoid-like cancer repositioned upward with the pexy or to the development of a new neoplasm arising on an internal polypoid pile, again lifted up after the stapled mucosectomy $[27,80]$. This troublesome event may be prevented with a careful selection of the patients, i.e. excising the long-standing polypoid hemorrhoids or sending the specimen for the histology routinely.

Penile trauma after active anal intercourse

Two heterosexual patients had severe penile trauma with wide excision of penile skin and dramatic bleeding requiring emergency hospitalization after active anal intercourse with companions who had undergone PPH. The trauma was caused by retained staples [81]. Anal intercourse may result in condom damage [82]. The message from these reports is that the surgeon has to inform patients and their partners about this potential complication and that is better not to perform $\mathrm{PPH}$ in persons who practice receptive anal sex [83].

Tenesmus and fecal urgency

Tenesmus affected $50 \%$ of the patients who underwent PPH for fourth-degree hemorrhoids one year after surgery in a prospective randomized trial that compared stapled hemorrhoidopexy with manual hemorrhoidectomy [19]. This rate dropped to $25 \%$ after six months in another study [84] but was not reported as a relevant problem in a recent metaanalysis [8]. In a non-randomized comparison between PPH and Milligan-Morgan procedure in the treatment of fourthdegree hemorrhoids, tenesmus was experienced in $32 \%$ of patients submitted to PPH but in none of those who underwent Milligan-Morgan procedure; the difference was statistically significant [56]. In a prospective study at 28 months of follow-up, fecal urgency was still affecting a large proportion $(40 \%)$ of patients, was disturbing or severe in $24 \%$ and significantly affected the patient's satisfaction more than any other symptom [28]. The frequency of urgency was lower but still present (14\%) after an 87-month median follow-up, more often than after conventional hemorrhoidectomy $(8 \%)$ [85]. This is likely to be due to a reduced rectal capacity, as shown by De Nardi et al. [86].
This complication can be prevented by avoiding PPH in patients with reduced rectal compliance or increased rectal sensation, assessed by anorectal physiology testing, and in patients with fourth-degree piles.

Treatment may consist of transanal electrostimulation or sensory biofeedback [87]. In cases resistant to conservative treatment, transanal agrapphectomy, aimed at removing fibrous tissue and increasing rectal capacity, may also be considered [54].

\section{Fecal incontinence}

Hemorrhoids are factors of anal continence as there is atrophy of anal the cushions in patients with idiopathic incontinence [88]. Therefore, the upper replacement instead of excision of the piles carried out by stapled hemorrhoidopexy should favor continence. It is a matter of fact that incontinence may follow $\mathrm{PPH}$, even if it is not frequent $[17,20]$. It may be limited to loss of flatus, but a temporary incontinence to stool has been reported in $3.2 \%$ of cases after PPH for fourth-degree piles and a higher fecal leakage rate up to $31 \%$ may be recorded [28, $30,89]$. Soiling was present in $10 \%$ of cases after one year [34] and decreased to $7 \%$ after 7 years [85].

Fecal soiling after PPH may be induced by a lowplaced staple line, as shown by a recent comparative study [90], or by fragmentation of the internal sphincter due to the large diameter $(36 \mathrm{~mm})$ of the circular anal dilatator in multiparous females with weak sphincters or in males with tight anus requiring forceful introduction of the device. Lesions of the internal sphincter following PPH have been observed at anal ultrasonography (US) by Ho et al. [91, 92], but not confirmed by Altomare et al. [93]. However, fecal soiling may also occur after manual hemorrhoidectomy, more likely after the MilliganMorgan than after the Ferguson procedure [94].

Preoperative anal manometry and anal US may help to detect patients with a less compliant rectum and weak sphincters, thus minimizing the risk of post-PPH incontinence. In case of soiling due to localized trauma of the internal sphincters, the use of bulking agents such as injectable silicone or carbon-coated microbeads, or the injection of autologous fat [95] may be of some advantage and achieves good results in up to $80 \%$ of cases [96]. Sphincter repair is rarely needed, and was carried only in two out of 65 reinterventions after PPH [27].

\section{Retropneumoperitoneum and pneumomediastinum}

These complications may be due either to filtration of air through the staple line to the extraperitoneal space (facil- 
itated by a wide excision of the rectal mucosa with a too deep purse string involving the whole rectal wall) or to leakage of bacterial content leading to pelvic sepsis and requiring a diverting stoma [23]. This complication may be low-symptomatic [24, 97] and require just conservative treatment with intravenous fluid and delayed oral intake, or may present with diffuse abdominal pain and high white blood cell count and respond to bowel rest and intravenous antibiotics [98]. Retroperitoneal air has also been reported after colonoscopy, transanal endoscopic microsurgery and transanal full-thickness excision of rectal tumors [99].

Rectal perforation, pelvic sepsis, rectal hematoma causing intestinal obstruction and other life-threathening complications

Life threatening complications after PPH are usually associated with anastomotic leakage or pelvic sepsis [22, 100-102]. Their frequency was 0.08 and $0.09 \%$ in two large series [20, 32]. Anastomotic dehiscence after PPH, which may lead to pelvic sepsis in case of full-thickness rectal stapling, was reported in $3.2 \%$ of 654 patients [26].

In a recent systematic review, McCloud et al. [103] reported 7 cases of life-threatening pelvic sepsis in 4 years, and 6 cases of pelvic sepsis after manual hemorrhoidectomy in 20 years. Of the 7 cases after PPH, 4 were associated with anastomotic dehiscence, 5 had perineal debridement (including the external sphincter in 2 cases), 4 required temporary fecal diversion and 2 required permanent fecal diversion. After permanent fecal diversion, one patient died of septic shock. Patients typically presented with urinary difficulties, fever, severe pain, septic shock and leukocytosis, usually within the first week after surgery but in one case after 39 days. It is unclear if an eighth case (a patient who died after perineal debridement and fecal diversion) reported by Herold in a one-year German survey of 4635 PPH [103] is the same case as reported by Bonner et al. [104] and included in McCloud et al.'s series [103]. The same German survey reported three rectal perforations requiring one permanent and two temporary stomas [53]. A case of pelvic sepsis leading to vena cava thrombosis and eventually requiring nephrectomy has also been reported [105]. Between 1999 and 2007 the FDA CDRH website [16] listed 38 cases of rectal perforation or staple line dehiscence during stapled hemorrhoidopexy (Table 1). In one case perforation was attributed to a too deep purse string while in 8 of the 10 cases where no error or device malfunctioning was noted the diagnosis was delayed. Ninenteen $(50 \%)$ of patients required an abdominal operation and $13(34 \%)$ patients required fecal diversion including one patient who underwent an abdomino perineal resection and one death from sepsis. None of these cases has been reported in the scientific literature. So, numerous life-threatening complications after $\mathrm{PPH}$ in a few years and a small number of pelvic sepsis after manual hemorrhoidectomy in a much longer period of time have been described. Considering that manual operations are more frequently used than $\mathrm{PPH}$, with a 4:1 ratio in Italy [106] where stapled hemorrhoidopexy is extremely popular, we may conclude that the rate of life-threatening complication is much lower after manual hemorrhoidectomy. The reason for this difference may well be the learning curve [53] and, if this is the case, the frequency of such serious complications should diminish as was the case for bile duct injury after laparoscopic cholecystectomy. Nevertheless, the gravity of these adverse events seems to be greater after PPH, since pelvic sepsis frequently requires a stoma while this is very rare after manual procedure [103].

Rectal perforation may be facilitated by a too deep insertion of the purse string, which causes a full-thickness transection of the rectal wall, prone to dehiscence, or by the fact that, in hemorrhoidal surgery, the rectum is not often mechanically cleansed. The staple line after PPH should be systematically checked and anastomotic defects should be promptly repaired. Use of perioperative antibiotic coverage seems to be justified.

Retroperitoneal and rectal hematoma causing intestinal obstruction and requiring a stoma have been reported $[102,107]$. On the other hand, even massive rectal wall hematoma diffusing to the whole pelvis and reaching the cecum may respond to transanal drainage by rectotomy.

Intestinal perforation and bleeding with hemoperitoneum due to an undiagnosed enterocele may occur [108]. In case of a patient with enterocele and a prolapsed Douglas pouch due to a previous hysterectomy, the surgeon should be alerted. PPH experts published a consensus article which suggests that enterocele is to be a contraindication to stapled haemorrhoidopexy [109].

\section{New trends for PPH}

There is now the tendency to restrict the use of PPH to the management of three- and four-quadrant thirddegree hemorrhoids, as recently suggested by the guidelines of the Italian Society of Colo-Rectal surgery [110]. For second-degree hemorrhoids, apart from rubber band ligation, a novel effective noninvasive technique (Doppler dearterialization) is available [111, 112]. For fourth-degree and thrombosed piles, most studies reported high complication and recurrence rates [19, 30, 56, 84]. The decreased use of PPH among members of 
SICCR, from $26 \%$ to $20 \%$ in the last three years [106, 113], might well reflect this trend towards a restriction of the indications.

STARR for advanced hemorrhoids has recently been proposed by Boccasanta et al. [62]. A combination of PPH with excision of anal tags and external piles has also been described [40].

Further studies on factors predicting the development of postoperative recurrence and complications are needed. The pathogenesis and the management of severe chronic proctalgia should also be investigated, as this condition may affect the quality of life of the patients.

Finally, evidence-based management of hemorrhoids should be promoted by the surgical community, since, at least in Europe, many young colleagues who have never performed a simple, safe and cost-effective rubber band ligation manage hemorrhoids mostly by performing PPH. Being taken by overenthusiasm for these "toys for boys" [114], surgeons may therefore abuse this new technology [115], putting the patients at risk of harmful overtreatment. Hopefully, the future trend will be the return to an old validated policy, by increasing use of the less invasive outpatient procedures and by decreasing the use of surgery.

\section{Complications following STARR}

Encouraging short-term results have been reported after STARR with good to excellent outcome in $91 \%$ of patients [116]. Other studies have shown persistence of symptoms in $44 \%$ of patients [14] and lack of improvement at mean follow-up of 20 months in $35 \%$ of patients [117].

The risk of adverse events and poor outcome following STARR may be increased by the presence of undiagnosed concomitant pelviperineal diseases which frequently affect constipated patients, such as anismus and enterocele; these are a contraindications to the procedure $[15$, 122, 123]. Large rectocele, digitation, anismus, sense of incomplete evacuation and lower bowel frequency are predictive of poor results [117] and psychological disorders may also negatively affect outcome [123]. Reintervention may be needed in $9 \%$ of patients due to postoperative complications and in $11 \%$ of patients due to recurrence of the disease [117].

Recently, Boccasanta et al. demonstrated that STARR was superior to PPH for the management of hemorrhoids associated with rectal internal mucosal prolapse [62]. Nevertheless a comparison with other, less expensive techniques for rectal mucosal prolapse, such as Park's hemorrhoidectomy [124], has not been carried out. Following STARR for hemorrhoids, postoperative bleed- ing occurred in $5.9 \%$, pile thrombosis in $2.9 \%$ and transient fecal urgency in $26.5 \%$ of cases [62].

\section{Rectal bleeding}

Postoperative rectal bleeding occurred in $11 \%$ of cases after STARR in a multicentric study [117] but was lower $(4.4 \%)$ in the European STARR Registry [125]. Rectal bleeding requiring reoperation occurs in $2.7 \%$ to $11 \%$ of patients $[116,117,126]$. A manual suture to reinforce the staple line minimizes the risk of bleeding after STARR. Such suture seems mandatory as the rate of intraoperative bleeding from the staple line during STARR is 95\% [11]. Delayed bleeding may be caused by a granuloma in $17 \%$ of cases [126] which may be surgically removed. Arroyo et al. [126] advocated the routine use of the new device (PPH03) to achieve a better hemostasis, despite the fact that $2.7 \%$ of their patients needed surgical reintervention. Some other authors disagree, as the amount of resected redundant tissue is less with the PPH03 [127].

\section{Anorectal stricture}

Anorectal stenosis is uncommon, occurring in $3 \%$ and $3.6 \%$ of the operated cases in two series [14, 128]. In another series, it was infrequent (1.2\%) and usually related to an anastomotic breakdown [125]. It has been successfully managed with dilation. In one case, anorectal stenosis was due to a hematoma of the rectovaginal septum [15]. A case of total rectal lumen obliteration after STARR has recently been reported [129].

Pelvic and anorectal pain

Pelvic pain remained unchanged after STARR in $20 \%$ of patients at one year [128]. De novo anorectal and pelvic pain developed in $9.5 \%$ of patients after STARR, more than expected, in a prospective multicentric study involving more than 1000 patients [125] and in $11 \%$ of patients in a retrospective multicentric study [117]. The pathogenesis of post-STARR proctalgia is similar to that reported after PPH, even though patients are more prone to develop rectal pain due to the full-thickness resection and the double staple line reducing rectal compliance and more likely to involve the richly innervated striated muscle fibers. Pain associated with deep retained staples has been recently reported in a patient reoperated after STARR, who had two staples attached to the puborectalis muscle [130].

Rectal pain also depends on psychological factors and may be related to psychological illness, as shown by Renzi 
and Pescatori [131]. Patients with obstructed defecation are depressed, anxious, or both, in $66 \%$ of cases [132]. Anismus, a multiorgan disorder also involving the central nervous system [132], is a contraindication to STARR that is often ignored [122]; it may increase rectal pain, but is mainly responsible for persisting constipation. This happened in a Greek series, and the colleagues had to send a third of their cases, six patients with anismus who failed after STARR, to a pelvic floor physiotherapist, with good results [14].

Neurosacral stimulation has been proven to be effective in some selective cases with chronic pain and might be used to deal with pain after STARR [134]. Again, agrapphectomy may effectively manage this complication [54].

\section{Rectal diverticulum}

This complication has been described recently and in this issue $[135,136]$ and its pathogenesis is similar to that described for the rectal pocket after PPH. It causes local discomfort to the patient and may entrap fecal matter, thus favoring the recurrence of obstructed defecation. It may be laid open if small or resected transanally if large.

\section{Urgency}

Patients are likely to complain of urgency and frequent defecations, due to a reduced rectal capacity, immediately after the procedure, but these symptoms tend to decrease with time [14]. However, urgency was still present in $23 \%$ of cases at a longer follow-up in a large multicentric series [125], in $22 \%$ at one year according Nicolas et al. [137] due to a significantly decreased maximal tolerable volume (74 instead of $120 \mathrm{ml}$ air). Urgency and frequent defecations were the most frequent reason for long-term patient dissatisfaction in one prospective series [14]. Urgency and low rectal compliance after STARR may be successfully treated with pelvic floor rehabilitation [138].

\section{Fecal incontinence}

Rates of de novo incontinence to flatus in prospective series range from $3 \%$ to $19 \%[11,116,126,139]$. Minor soiling occurred in $16 \%$ of patients [14] with Wexner incontinence scores between 1 and 4 [14, 126]. In two reports, incontinence to flatus disappeared at longer follow-up [116, 126]. Fecal incontinence may be due to a device-related fragmentation of the internal sphincter, a complication already reported after PPH [92]. Moreover, fecal incontinence may be neurogenic, due either to a vaginal multiparity or to chronic straining with consequent stretch of the pudendal nerves [140], two conditions often encountered in constipated patients undergoing STARR. Previous hysterectomy, not infrequent in constipated patients who do not respond to conservative treatment and are therefore candidates for surgery, may also damage the pericervical plexus involving anorectal innervation. Hysterectomized women, therefore, are more prone to fecal incontinence [141]. Finally, impaired rectal compliance has been reported after STARR [14], which may contribute to fecal incontinence by reducing the rectal reservoir [142]. Due to a significant decrease in anal resting tone and maximum tolerable volume (seen at postoperative anal manometry), new onset fecal incontinence developed in 5 of 36 patients $(14 \%)$ one year after STARR [137].

Anal manometry, anovaginal US, and pudendal nerve terminal motor latency may help to detect causes of fecal incontinence [143]. Transanal electrostimulation and, possibly, sacral neuromodulation [144] may help in treating such conditions. Bulking agents, such as carbon-coated microbeads, have also been been successfully used [145]. Levatorplasty was carried out in 2 of the 4 patients we had to reoperate for incontinence after STARR at our unit, but the outcome was poor, as frequently happens after sphincteroplasty in hysterectomized multiparous women with denervated pelvic floor muscles [146].

Biofeedback and physiokinesitherapy may also help in the management of these patients $[87,117,138]$.

\section{Rectovaginal fistula}

Rectovaginal fistula occurred after STARR three times in a group of 38 referred cases [117], whereas it has not been reported at all in over 1000 cases in a large multicentric prospective study by Stuto et al. [125]. It may or may not require a reintervention [147] and may be caused by ischemia or a hematoma in the recto-vaginal septum [122] rather than by a direct intraoperative trauma. When surgery is indicated, the success rate after repair of a rectovaginal fistula is around $80 \%$ [148] and the formation of a diverting stoma may minimize failure in case of complex repair [117, 149].

An accurate examination of the vagina during and after surgery, and its protection with a retractor, are aimed at minimizing the risk of this complication, but again, the intraoperative integrity of the vagina does not exclude the late occurrence of a fistula [121].

\section{Rectal perforation and pelvic sepsis}

The risk of dehiscence of the staple line is higher than after PPH, as the STARR procedure consists of two complete rectotomies. Dehiscence may give origin to either an 
intra- or an extrarectal fistula which requires lay-open [135]. Recently, a fatal case of pelvic gangrene was reported; therefore, antibiotic prophylaxis seems advisable when performing STARR [117].

A Hartmann operation in a patient with a pelvic sepsis due to a gross breakdown of the staple line after STARR has been reported [150]. Even if the procedure has just recently been introduced in the United States, two cases of rectal perforation one requiring colostomy have been reported to the FDA [16].

New trends for STARR procedure

A transanal Contour stapler (Ethicon Endosurgery, Cincinnati, USA), that is able to resect more tissue under direct vision compared to the $\mathrm{PPH}$, is being clinically validated prior to being proposed to the surgical community. The STARR procedure was introduced in clinical practice and was widely used before being appropriately evaluated [150]. As far as obstructed defecation is concerned, conservative measures (such as pelvic floor rehabilitation, psychotherapy and rectal irrigation [152]) and less invasive surgical procedures (such as sacral neuromodulation [134, 153, 154]) are unlikely to be dangerous for patients and their success rates are similar to those after any kind of surgery in the medium and long terms $[14,155,120]$. A modern concept is that obstructed defecation is an iceberg syndrome in which the evident lesions such as rectocele and internal prolapse, usually the target of surgery, are the emerging tip, and the "underwater rocks" or occult lesions may be the main causes of symptoms [131]. As the latter are mainly functional and not responding to surgical treatment, a more conservative policy may well be recommended to the surgical community.

Since chronic constipation is a multifactorial disease, often psychosomatic, the approach to this condition should be more holistic and should take in account the Psychoneuroendocrinimmunology (PNEI) system. Constipated patients, in fact, may have psychological distress (e.g. depression), neurological disorders (e.g. hypoganglionosis), endocrine alterations (e.g. hypothyroidism), and immunological disturbances (e.g. failure of the cytokine barrier) [156]. Surgery, including stapled rectotomy, should be reserved for those anatomical anomalies which are advanced, irreversible and clear concauses of constipation.

STARR experts improved the state of the art by publishing a consensus papers aimed at suggesting precise contraindications [122]; they concluded that those who perform these operations have to be colorectal surgeons trained in transanal stapling $[109,122]$. Apart from anismus, enterocele and possibly mental illness, another contraindication to the STARR procedure is a weak sphincter, as up to $23 \%$ of those who have this operation may expe- rience incontinence or urgency [139]. The frequency of new onset incontinence after manual rectocele repair, instead, is between $0 \%$ and $8 \%[157,158]$ and vaginal repairs carry no risk of incontinence.

Interestingly, Petersen et al. [159] were able to perform STARR and concomitant laparoscopic enterocele repair. Nevertheless, we reported poor functional results of STARR in patients with enteroceles, likely due to failure of the supporting structures [117]. So, again, paradoxically, the new trend is to re-evaluate an old type of management, less risky than the novel one.

\section{Conclusions}

PPH and STARR are widely used operations for the management of hemorrhoids and obstructed defecation. Therefore, surgeons should be well aware of the type and management of postoperative complications.

Common complications are rectal bleeding and fecal incontinence, which are also reported after conventional manual surgeries. Uncommon complications are rectal perforation, rectovaginal fistula and retropneumoperitoneum, which are increasingly reported after these new operations and may well be the effect of a learning curve. Anismus and enterocele represent contraindications to PPH and STARR, while fourth-degree hemorrhoids should be a contraindication to PPH.

As the best and most inexpensive policy is prevention, meticulous technique and an accurate selection of patients may decrease the risk of adverse events. Once occurred, complications may be managed with a wide range of nonsurgical as well as surgical techniques.

The outcome of reintervention is more favorable following complicated PPH than after complicated STARR, as patients with obstructed defecation are more likely to have associated occult pelviperineal disease and psychological disorders, which may affect the outcome of surgery and are frequently underestimated. The risks connected with both PPH and STARR make mandatory that these two appealing procedures be carried out by surgeons specialized in colorectal surgery. Surgeons operating for obstructed defecation should seek the cooperation of a multidisciplinary team. By doing so, an improved outcome of both PPH and STARR should be expected.

Acknowledgements The authors thank Dr. Marina Fiorino for her valuable help with preparation of the manuscript.

\section{References}

1. Pescatori M, Favetta U, Dedola S, Orsini S (1997) Transanal stapled excision of rectal mucosal prolapse. Tech Coloproctol 1:96-98 
2. Longo A (1998) Treatment of haemorrhoidal disease by reduction of mucosal and haemorrhoidal prolapse with a circular-suturing device: a new procedure. In: Proceedings of the Sixth World Congress of Endoscopic Surgery. Monduzzi Editori, Rome, pp 777-784

3. Mehigan BJ, Monson JRT, Hartley JE (2000) Stapling procedure for haemorrhoids versus Milligan Morgan haemorrhoidectomy: randomized controlled trial. Lancet 335:784-785

4. Rowsell M, Bello M, Hemingway DM (2000) Circumferential mucosectomy (stapled haemorrhoidectomy) versus conventional haemorrhoidectomy; randomized controlled trial. Lancet 355:779-781

5. Thaha MA, Irvine LA, Steele RJ, Campbell KL (2005) Postdefecation pain syndrome after circular stapled anopexy is abolished by oral nifedipine. Br J Surg 92:208-210

6. Thaha MA, Kazmi SA, Binnie NR et al (2004) Duration of pain and its influence on return to work following haemorrhoid surgery: results of multi-centre randomised controlled trial comparing circular stapled anopexy and Ferguson closed hemorrhoidectomy. Br J Surg 91[Suppl 2]

7. Nisar PJ, Acheson AG, Neal K, Scholefield JH (2004) Stapled haemorrhoidopexy compared with conventional haemorrhoidectomy: systematic review of randomized controlled trials. Dis Colon Rectum 47:1837-1845

8. Jayaraman S, Colquhoun PH, Malthaner RA (2007) Stapled haemorrhoidopexy is associated with a higher long-term recurrence rate of internal hemorrhoids compared with conventional excisional hemorrhoidal surgery. Dis Colon Rectum 50:1297-1305

9. Cataldo P, Ellis CN, Gregorcyk S et al (2005) Practice parameters for the management of haemorrhoids (revised). Dis Colon Rectum 48:189-194

10. Tjandra JJ, Chan MK (2007) Systematic review on the procedure for prolapse and hemorrhoids (stapled haemorrhoidopexy). Dis Colon Rectum 50:878-892

11. Boccasanta P, Venturi M, Stuto A et al (2004) Stapled transanal rectal resection for outlet obstruction: a prospective, multicenter trial. Dis Colon Rectum 47:1285-1296

12. Meurette G, Regenet N, Frampas E, Lehur PA (2007) Is functional outcome explained by anatomical modifications after stapled transanal resection (STARR) for obstructed defecation syndrome (ODS)? Dis Colon Rectum 50:747-748

13. Vermeulen J, Lange JF, Sikkenk AC, van der Harst E (2005) Anterolateral rectopexy for correction of rectoceles leads to goods anatomical but poor functional results. Tech Coloproctol 9:35-41

14. Pechlivanides G, Tsiaoussis J, Athanasakis E et al (2007) Stapled transanal rectal resection (STARR) to reverse the anatomic disorders of pelvic floor dyssynergia. World J Surg 31:1329-1335

15. Dodi G, Pietroletti R, Milito G, Binda GA, Pescatori M (2003) Bleeding, incontinence, pain and constipation after STARR transanal double stapling rectotomy for obstructed defecation. Tech Coloproctol 7:148-153

16. http://www.fda.gov/cdrh/index.html (accessed 2 October 2007)

17. Senagore AJ, Singer M, Abcarian H (2004) A prospective, randomized, controlled multicenter trial comparing stapled haemorrhoidopexy and Ferguson hemorrhoidopexy: perioperative and one-year results. Dis Colon Rectum 47:1824-1836

18. Beattie GC, McAdam TK, McIntosh SA, Loudon MA (2006) Day case stapled haemorrhoidopexy for prolapsing haemorrhoids. Colorectal Dis 8:56-61

19. Ortiz H, Marzo J, Armendariz P, De Miguel M (2005) Stapled hemorrhoidopexy vs. diathermy excision for fourth-degree hemorrhoids: a randomized, clinical trial and review of the literature. Dis Colon Rectum 48:809-815

20. Ravo B, Amato A, Bianco V et al (2002) Complications after sta- pled haemorrhoidectomy; can they be prevented? Tech Coloproctol 6:83-88

21. Cipriani S, Pescatori M (2002) Acute rectal obstruction after PPH stapled haemorrhoidectomy. Colorectal Dis 4:367-370

22. Wong LY, Jiang JK, Chang SC, Lin JK (2003) Rectal perforation: a life-threatening complication of stapled hemorrhoidectomy: report of a case. Dis Colon Rectum 46:116-117

23. Ripetti V, Caricato M, Arullani A (2002) Rectal perforation, retropneumoperitoneum, and pneumomediastinum after stapling procedure for prolapsed haemorrhoids: report of a case and subsequent consideration. Dis Colon Rectum 45:268-270

24. Filingieri V, Gravante G (2005) Pneumoretroperitoneum, pneumomediastinum and subcutaneous emphysema of the neck after stapled hemorrhoidopexy. Tech Coloproctol 9:86

25. http://www.camera.it/_dati/leg14/lavori/stenografici/sed587/ bt41.htm (accessed 12 February 2008)

26. Jongen JL, Bock JU, Peleikis HG, Eberstein A, Pfister K (2006) Complication and reoperation in stapled anopexy: learning by doing. Int J Colorectal Dis 21:166-171

27. Brusciano L, Ayabaca SM, Pescatori M et al (2004) Reinterventions after complicated and failed stapled haemorrhoidopexy. Dis Colon Rectum 47:1846-1851

28. Fueglistaler P, Guenin MO, Montali I et al (2007) Long-term results after stapled hemorrhoidopexy: high patient satisfaction despite frequent postoperative symptoms. Dis Colon Rectum 59:204-212

29. Ceulemans R, Creve U, Van Hee R, Martens C, Wuyts SL (2000) Benefit of emergency hemorrhoidectomy. A comparison with results after elective operations. Eur J Surg 166:808-812

30. Finco C, Sarzo G, Savastano S, Degregori S, Merigliano S (2006) Stapled haemorrhoidopexy in fourth degree haemorrhoidal prolapse: is it worthwhile? Colorectal Dis 8:130-134

31. Ng KH, Seow-Choen F, Tang CL, Heah SM, Ooi SS (2004) Stapled hemorrhoidectomy. Our experience with more than 3000 cases. Colorect Dis 6[Suppl 2]:8 (abstract)

32. Ng KH, Ho KS, Ooi BS, Tang CL, Eu KW (2006) Experience of 3711 stapled haemorrhoidectomy operations. Br J Surg 93:226-230

33. Angelone G, Giardiello C, Prota C (2006) Stapled hemorrhoidopexy. Complications and 2-year follow-up. Chir Ital 58:753-760

34. Gravie JF, Lehur PA, Huten N et al (2005) Stapled hemorrhoidopexy versus Milligan-Morgan hemorrhoidectomy: a prospective, randomized, multicenter trial with 2-year postoperative followup. Ann Surg 242:29-35

35. Huang WS, Lin PY, Chin CC et al (2007) Stapled hemorrhoidopexy for prolapsed hemorrhoids in patients with liver cirrhosis; a preliminary outcome for 8-case experience. Int J Colorectal Dis 22:1083-1089

36. Brown SR, Ballan K, Ho E, Ho Fams YH, Seow-Choen F (2001) Stapled mucosectomy for acute thrombosed circumferentially prolapsed piles: a prospective randomized comparison with conventional haemorrhoidectomy. Colorectal Dis 3:175-178

37. Bufo A, Galasse S, Amoroso M (2006) Recurrent postoperative bleeding after stapled hemorrhoidopexy requiring emergency laparotomy. Tech Coloproctol 10:62-63

38. Conzo G, Buffardi R, Brancaccio U et al (2004) Stapled hemorrhoidopexy in the treatment of hemorrhoidal prolapse. Ann Ital Chir 75:655-659

39. Brown SR, Shanmugan P, Dobbs P (2006) Stapled hemorrhoidopexy for prolapsing hemorrhoids. Colorect Dis 8:525-526 (letter)

40. Martinsons A, Narbuts Z, Brunenieks I, Pavars M, Lebedkovs S, Gardovskis J (2007) A comparison of quality of life and postoperative results from combined $\mathrm{PPH}$ and conventional haemorrhoidectomy in different cases of haemorrhoidal diseases. Colorectal Dis 9:423-429 
41. Aigner F, Bodner G, Grubert H et al (2006) The vascular nature of hemorrhoids. J Gastrointest Surg 10:1044-1050

42. Shalaby R, Desoky A (2001) Randomized clinical trial of stapled versus Milligan-Morgan haemorrhoidectomy. $\mathrm{Br}$ J Surg 88:1049-1053

43. Boccasanta P, Capretti PG, Venturi M et al (2001) Randomised controlled trial between stapled circumferential mucosectomy and conventional circular hemorrhoidectomy in advanced hemorrhoids with external mucosal prolapse. Am J Surg 182:64-68

44. Correa-Rovelo JM, Tellez O, Obregon L, Miranda-Gomez A, Moran S (2002) Stapled rectal mucosectomy vs. closed hemorrhoidectomy: a randomized, clinical trial. Dis Colon Rectum 45:1367-1374

45. Palimento D, Picchio M, Attanasio U, Lombardi A, Bambini C, Renda A (2003) Stapled and open hemorrhoidectomy: randomized controlled trial of early results. World J Surg 27:203-207

46. Correa-Rovelo JM, Tellez O, Obregón L et al (2003) Prospective study of factors affecting postoperative pain and symptom persistence after stapled rectal mucosectomy for hemorrhoids: a need for preservation of squamous epithelium. Dis Colon Rectum 46:955-962

47. Cheetham MJ, Cohen CR, Kamm MA, Phillips RK (2003) A randomized controlled trial of diathermy hemorrhoidectomy vs stapled hemorrhoidectomy in an intended day-case setting with longer-term follow-up. Dis Colon Rectum 46:491-497

48. Cheetham MJ, Mortensen NJ, Nystrom PO, Kamm MA, Phillips RK (2000) Persistent pain and fecal urgency after stapled haemorrhoidectomy. Lancet 356:730-733

49. Oughriss M, Yver R, Faucheron JL (2005) Complications of stapled hemorrhoidectomy: a French multicentric study. Gastroenterol Clin Biol 29:429-433

50. Pescatori M (2000) Persistent pain after stapled haemorrhoidectomy. Lancet 356:2188 (letter)

51. Jongen JH, Bock JU (2000) Pain after stapled haemorrhoidectomy Lancet 356:2187 (letter)

52. Rowsell M, Bello M, Hemingway DM (2000) Pain after stapled haemorrhoidectomy. Lancet 356:2188 (letter)

53. Herold A, Kirsch JJ (2000) Pain after stapled haemorrhoidectomy. Lancet 356:2187 (letter)

54. Wunderlich M, Freitas A, Langmayr J, Lechner M, Tentschert G (2004) Anal incontinence after hemorrhoidectomy. J Urol Urogynakol 11:31-33

55. Shanmugam V, Watson AJ, Chapman AD, Binnie NR, Loudon MA (2005) Pathological audit of stapled haemorhoidopexy. Colorectal Dis 7:172-175

56. Mattana C, Coco C, Manno A et al (2007) Stapled hemorrhoidopexy and Milligan Morgan hemorrhoidectomy in the cure of fourth-degree hemorrhoids: long-term evaluation and clinical results. Dis Colon Rectum 50:1770-1775

57. Mauillon J, Thoumas D, Leroi AM, Freger P, Michot F, Denis P (1999) Results of pudendal nerve neurolysis-transposition in twelve patients suffering from pudendal neuralgia. Dis Colon Rectum 42:186-192

58. Fondran JC, Porter JA, Slezac FA (2006) Inflammatory polyps: a cause of late bleeding in stapled hemorrhoidectomy. Dis Colon Rectum 49:1910-1913

59. Koh DC, Cheong DM, Wong KS (2005) Stapled hemorrhoidectomy: bothersome staple line bleeding. Asian J Surg 28:193-197

60. Drummond R, Wright DM (2007) Continued rectal bleeding following stapled hemorrhoidectomy. Colorectal Dis 9:669-670

61. Quah HM, Hadi HI, Hay DJ, Maw A (2003) Residual staples as possible cause of recurrent rectal bleeding after stapled hemorrhoidectomy. Colorect Dis 5:196 (letter)

62. Boccasanta P, Venturi M, Roviaro G (2007) Stapled transanal rectal resection versus stapled anopexy in the cure of hemorrhoids associated with rectal prolapse. A randomized controlled trial. Int J Colorectal Dis 22:245-251
63. Huang WS, Chin CC, Yeh CH, Lin PY, Wang JY (2007) Randomized comparison between stapled hemorrhoidopexy and Ferguson hemorrhoidectomy for grade III hemorrhoids in Taiwan: a prospective study. Int J Colorectal Dis 22:955-961

64. Arroyo A, Perez-Vicente F, Serrano P, Candela F, Perez Vazquez MT, Calpena R (2006) Proctitis complicating stapled hemorrhoidectomy: report of a case. Int J Colorectal Dis 21:197-198

65. Slawik S, Kenefick N, Greenslade GL, Dixon AR (2007) A prospective evaluation of stapled haemorrhoidopexy/rectal mucosectomy in the management of 3rd and 4th degree haemorrhoids. Colorectal Dis 9:352-356

66. Lan P, Wu X, Zhou X, Wang J, Zhang L (2006) The safety and efficacy of stapled hemorrhoidectomy in the treatment of hemorrhoids: a systematic review and metanalysis of ten randomized control trials. Int J Colorect Dis 21:172-178

67. Kanellos I, Blouhos K, Demetriades H, Pramateftakis MG, Betsis D (2004) Pneumomedistinum after dilatation of anal stricture following stapled haemorrhoidopexy. Tech Coloproctol 8:185-187

68. Yao L, Zhong Y, Xu J, Xu M, Zhou P (2006) Rectal stenosis after procedures for prolapse and hemorrhoids $(\mathrm{PPH})$ - a report from China. World J Surg 30:1311-1315

69. Pescatori M (2002) Management of post-anopexy rectal stricture. Tech Coloproctol 6:125-126

70. Hetzer FH, Demartines N, Handschin AE, Clavien PA (2002) Stapled vs excision hemorrhoidectomy: long-term results of a prospective randomized trial. Arch Surg 137:337-340

71. Racalbuto A, Aliotta I, Corsaro G, Lanteri R, Di Cataldo A, Licata A (2004) Hemorrhoidal stapler prolapsectomy vs Milligan-Morgan hemorrhoidectomy: a long-term randomized trial. Int J Colorectal Dis 19:239-244

72. Ng KH, Eu KW, Ooi BS, Heah SM, Tang CL, Seow-Choen F (2003) Stapled haemorrhoidopexy for prolapsed piles performed with concurrent perianal conditions. Tech Coloproctol 7:214-215

73. Huang WS, Chin CC, Yeh CH, Lin PY, Wang JY (2007) The late onset of an anal abscess caused by a chicken bone that complicated stapled hemorrhoidopexy Int. J Colorectal Dis 22:1291-1292

74. McDonald PJ, Bona R, Cohen CR (2004) Rectovaginal fistula after stapled haemorrhoidopexy. Colorectal Dis 6:64-65 (letter)

75. Pescatori M (2003) PPH stapled hemorrhoidectomy - a cautionary note. Dis Colon Rectum 46:131 (letter)

76. Cipriani S, Pescatori M (2002) Acute rectal obstruction after PPH stapled haemorrhoidectomy. Colorectal Dis 4:367-370

77. Giordano P, Bradley B, Peiris L (2008) Stapled closure of the rectal lumen following stapled haemorrhoidopexy: case report. Dis Colon Rectum (in press)

78. Brown S, Baraza W, Shorthouse A (2008) Total rectal lumen obliteration after stapled haemorrhoidopexy: a cautionary tale. Tech Coloproctol 11:357-358

79. Pescatori M, Spyrou M, Cobellis L, Bottini C, Tessera G (2006) Rectal pocket syndrome after stapled mucosectomy. Colorectal Dis 8:808-811

80. Watson AJM, McLaren CM, Chapman AD, Binnie NR, Loudon MA (2003) Further cautionary tales from histopathology of stapled haemorrhoidectomy specimen. Colorectal Dis 5:270-272

81. Capomagi A, Mannetta V, Balestrieri A et al (1999) Circular haemorrhoidectomy using stapler is the "gold standard" for the treatment of hemorrhoids? Preliminary data regarding 206 consecutive patients. Ital J Coloproctol 2:782-785

82. Kekez T, Bulic K, Smudj D, Majerovic M (2007) Is stapled hemorrhoidopexy safe for the male homosexual patient? Report of a case. Surg Today 37:335-337

83. Mlakar B (2007) Should we avoid stapled hemorrhoidopexy in 
males and females who practice receptive annal sex? Dis Colon Rectum 50:1727 (letter)

84. Zacharakis E, Kanellos D, Pramateftakis et al (2007) Long-term results after stapled haemorrhoidopexy for fourth-degree haemorrhoids: a prospective study with median follow-up of 6years. Tech Coloproctol 11:144-147

85. Ganio E, Altomare DF, Milito G, Gabrielli F, Canuti S (2007) Long-term outcome of a multicentre randomized clinical trial of stapled haemorrhoidopexy versus Milligan-Morgan haemorrhoidectomy. Br J Surg 94:1033-1037

86. De Nardi P, Corsetti M, Passaretti S, Testoni P, Staudacher C (2007) Evaluation of sensory and motor rectal response after hemorrhoidopexy with electronic barostat. Dis Colon Rectum 50:789 (abstract)

87. Pucciani F, Iozzi L, Masi A, Cianchi F, Cortesini C (2003) Multimodal rehabilitation for faecal incontinence: experience of an Italian centre devoted to faecal disorder rehabilitation. Tech Coloproctol 7:139-147

88. Thekkinkattil D, Gonsalves S, Lim M et al (2007) Role of anal cushions in idiopathic fecal incontinence. Dis Colon Rectum 50:749 (abstract)

89. Perez-Vicente F, Arroyo A, Serrano P, Candela F, Sanchez A, Calpena R (2006) Prospective randomised clinical trial of single versus double purse-string stapled mucosectomy in the treatment of prolapsed haemorrhoids. Int J Colorectal Dis 21:38-43

90. Pigot F, Dao-Quang M, Castinel A et al (2006) Low haemorrhoidopexy staple line does not improve results and increases risk for incontinence. Tech Coloproctol 10:329-333

91. Ho YH, Seow-Choen F, Tsang C, Eu KW (2001) Randomized trial assessing anal sphincter injuries after stapled haemorrhoidectomy Br J Surg 88:1449-1455

92. Ho YH, Tsang C, Tang CL, Nyam D, Eu KW, Seow-Choen F (2000) Anal sphincter injuries from stapling instrumentum introduced transanally: randomized controlled study with endoanal ultrasound and anorectal manometry. Dis Colon Rectum 43:169-173

93. Altomare DF, Rinaldi M, Sallustio PL, Martino P, De Fazio M, Memeo V (2001) Long-term effects of stapled haemorrhoidectomy on internal anal function and sensitivity. $\mathrm{Br} \mathrm{J}$ Surg $88: 1487-1491$

94. Johannsson HO, Pahlman L, Graf W (2006) Randomized clinical trial of the effects on anal function of Milligan-Morgan versus Ferguson haemorrhoidectomy Br J Surg 93:1208-1214

95. Bernardi C, Favetta U, Pescatori M (1998) Autologus fat injection for treatment of fecal incontinence: manometric and echographic assessment. Plast Reconstr Surg 102:1626-1628

96. Chan MK, Tjandra JJ (2006) Injectable silicone biomaterial (PTQ) to treat fecal incontinence after hemorrhoidectomy. Dis Colon Rectum 49:433-439

97. Mathur P, Ng KH, Seow-Choen F (2004) Stapled mucosectomy for rectocele repair: a preliminary report. Dis Colon Rectum 47:1978-1980

98. Delgadillo X, Renggli J, Becciolini C (2007) Severe complications after stapled hemorrhoidectomy: case report and review of the literature. Colorectal Dis 9[Suppl 3]:51

99. Basso L, Pescatori M (2003) Subcutaneus emphysema after associated colonoscopy and transanal excision of rectal adenoma. Surg Endosc 17:1677

100. Molloy RG, Kingsmore D (2000) Life threatening pelvic sepsis after stapled haemorrhoidectomy. Lancet 355:810

101. Maw A, Eu KW, Seow-Cohen F (2002) Retroperitoneal sepsis complicating stapled hemorrhoidectomy. Dis Colon Rectum 45:826-828

102. Vasudevan SP, Mustafa El A, Gadhvi VM, Jhaldyal P, Saharay M (2007) Acute intestinal obstruction following stapled haemorrhoidopexy. Colorectal Dis 9:669 (letter)
103. McCloud JM, Jameson JS, Scott AN (2006) Life-threatening sepsis following treatment for haemorrhoids: a systematic review. Colorectal Dis 8:748-755

104. Bönner C, Prohm P, Störkel S (2001) [Fournier gangrene as a rare complication after stapled hemorrhoidectomy. Case report and review of the literature]. Chirurg 72:1464-1466 (article in German)

105. Nemati Fard M (2006) Sardinian Congress of the Italian Society of Colo-Rectal Surgery. Tech Coloproctol 10:383-384

106. Bruni T, Occelli G (2006) The Italian Society of Colo-Rectal Surgery (SICCR) Annual Report of the Coloproctology Units (UCP Club). Tech Coloproctol 10:274-275

107. Meyer P, Stieger R (2004) Retroperitoneal hematoma due to seam insufficiency after stapled hemorrhoidectomy. Chirurg 75:1125-1127

108. Aumann G, Petersen S, Pollack T, Hellmich G, Ludwig K (2004) Severe intra-abdominal bleeding following stapled mucosectomy due to enterocele: report of a case. Tech Coloproctol $8: 41-43$

109. Corman ML, Gravié GF, Hager T et al (2003) Stapled haemorrhoidectomy: a consensus position paper by an international working party - indications, contra-indications and technique. Colorectal Dis 5:304-310

110. Altomare DF, Roveran A, Pecorella G, Gaj F, Stortini E (2006) The treatment of hemorrhoids: guidelines of the Italian Society of Colorectal Surgery. Tech Coloproctol 10:181-186

111. Felice G, Privitera A, Ellul E, Klaumann M (2005) Doppler-guided hemorrhoidal artery ligation: an alternative to hemorrhoidectomy. Dis Colon Rectum 48:2090-2093

112. Sohn N, Aronoff JS, Cohen FS, Weinstein MA (2001) Transanal hemorrhoidal dearterialization is an alternative to operative hemorrhoidectomy. Am J Surg 182:515-519

113. Bruni T, Occelli G (2005) The Italian Society of Colo-Rectal Surgery (SICCR) Annual Report of the Coloproctology Units (UCP Club). Tech Coloproctol 9:262-263

114. Thomson HW (2001) Manually operated. Ann R Coll Surg Engl 83[Suppl]:203

115. Pescatori M, Seow-Choen F (2003) Use and abuse of new technologies in colorectal surgery. Tech Coloproctol 7:1-2

116. Renzi A, Izzo D, Di Sarno G, Izzo G, Di Martino N (2006) Stapled transanal rectal resection to treat obstructed defecation caused by rectal intussusception and rectocele. Int $\mathrm{J}$ Colorectal Dis 21:661-667

117. Gagliardi G, Pescatori M, Altomare DF et al (2007) Factors predicting outcome after stapled transanal rectal resection (STARR) procedure for obstructed defecation. Dis Colon Rectum [epub ahead of print] PMID: 18157718

118. http://www.emorroidiestipsi.com. Last accessed December 12, 2007

119. Binda GA, Pescatori M, Romano G (2005) The dark side of double-stapled transanal rectal resection. Dis Colon Rectum 48:1830-1831 (letter)

120. Pescatori M, Boffi F, Russo A, Zbar AP (2006) Complications and recurrence after excision of rectal internal mucosal prolapse for obstructed defaecation. Int J Colorectal Dis 21:160-165

121. Bassi R, Rademacher J, Savoia A (2006) Rectovaginal fistula after STARR procedure complicated by haematoma of the posterior vaginal wall: report of a case. Tech Coloproctol 10:361-363

122. Corman ML, Carriero A, Hager T et al (2006) Consensus conference on the stapled transanal rectal resection (STARR) for disorders defaecation. Colorectal Dis 8:98-101

123. Senagore A, Gallagher J, Hull T, Ferrara A (2005) A short term assessment of the efficay of the STARR procedure for obstructed defecation syndrome. Dis Colon Rectum 48:234 (abstract) 
124. Rosa G, Lolli P, Piccinelli D et al (2005) Submucosal reconstructive hemorrhoidectomy (Parks' operation): a 20-year experience. Tech Coloproctol 9:209-214

125. Stuto A, Schwander O, Jayne D (2007) Assessing safety of the STARR procedure for ODS: preliminary results of the European STARR Registry. Dis Colon Rectum 50:724 (abstract)

126. Arroyo A, Perez-Vicente F, Serrano P et al (2007) Evaluation of stapled transanal rectal resection technique with two staplers in the treatment of obstructive defaecation syndrome. J Am Coll Surg 204:56-63

127. Bernie WA (2007) Stapled transanal rectal resection procedure. J Am Coll Surg 205:19 (letter)

128. Ellis CN (2007) Stapled transanal rectal resection (STARR) for rectocele. J Gastrointest Surg 11:153-154

129. Duchac V, Horak L, Stukavec J (2007) Blind closure of the rectum: an exceptional complication of STARR procedure. Colorectal Dis 9[Suppl 3]:22 (abstract)

130. De Nardi P, Bottini C, Faticanti Scucchi L, Palazzi A, Pescatori M (2007) Proctalgia in a patient with staples retained in the puborectalis muscle after STARR operation. Tech Coloproctol 11:353-356

131. Renzi C, Pescatori M (2000) Psychologic aspects in proctalgia. Dis Colon Rectum 43:535-539

132. Pescatori M, Spyrou M, Pulvirenti d'Urso A (2006) A prospective evaluation of occult disorders in obstructed defecation using the 'iceberg diagram'. Colorectal Dis 8:785-789

133. Bouchoucha M, Devroede G, Arsac M (2004) Anismus: a marker of multi-site functional disorders? Int J Colorectal Dis 19:374-379

134. Dudding TC, Vaizey CJ, Jarret ME, Cohen RG, Kamm MA (2007) Permanent sacral nerve stimulation for treatment of functional anorectal pain: a report of a case. Dis Colon Rectum 50:1275-1278

135. Boffi F (2007) Rectal stricture, pocket and fistula after STARR procedure: lay-open, curettage and rectal advancement flap. Tech Coloproctol 11:195

136. Sciaudone G, Di Stazio C, Guadagni I, Selvaggi F (2008) Rectal diverticulum: a new complication of STARR procedure for obstructed defecation. Tech Coloproctol 12:61-63

137. Nicolas R, Meurette G, Frampas E et al (2004) Stapled transanale rectal resection is efficient to correct obstructed defecation syndrome but could compromise anal continence. Colorectal Dis 6 [Suppl 2]:35 (abstract)

138. Pucciani F, Ringressi RM, Giani J (2007) Persistent dyschezia after double stapled transanal rectal resection for outlet obstruction: four case reports. Pelviperineology 26:132-135

139. Boccasanta P, Venturi M, Salamina G, Cesana BM, Bernasconi F, Roviaro G (2004) New trends in the surgical treatment of outlet obstruction: clinical and functional results of two novel transanal stapled techniques from a randomised controlled trial. Int J Colorectal Dis 19:359-369

140. Kiff ES, Swash M (1984) Slowed conduction in the pudendal nerves in idiopathic (neurogenic) faecal incontinence. Br J Surg 71:614-616

141. Forsgren C, Zetterstrom J, Lopez A, Nordnstam J, Anzen B, Altman D (2007) Effects of hysterectomy on bowel function: a three-year, prospective cohort study. Dis Colon Rectum
50:1139-1145

142. Williams JG, Rothenberger DA, Madoff RD, Goldberg SM (1992) Treatment of rectal prolapse in the elderly by perineal rectosigmoidectomy. Dis Colon Rectum 35:830-834

143. Beer-Gabel M, Frudinger A, Zbar AP (2005) Ultrasound in coloproctologic practice. In: Wexner SD, Zbar AP, Pescatori M (eds) Complex anorectal disorders. Springer, Berlin Heidelberg New York, pp 747-760.

144. Ripetti V (2006) Efficacy of sacral nerve stimulation for fecal incontinence: results of a multicenter double-blind crossover study. Tech Coloproctol 10:159-160

145. Spyrou M, De Nardi P (2005) Fecal incontinence after stapled transanal rectotomy managed with Durasphere injection. Tech Coloproctol 9:87

146. Baeten C, Bartolo DC, Lehur PA et al (2007) Consensus conference on fecal incontinence. Tech Coloproctol 11:128-134

147. Pescatori M, Dodi G, Salafia C, Zbar AP (2005) Rectovaginal fistula after double-stapled transanal rectotomy (STARR) for obstructed defaecation. Int J Colorectal Dis 20:83-85

148. Gagliardi G, Pescatori M (2007) Clinical and functional results after tailored surgery for rectovaginal fistula. Pelviperineology 26:78-81

149. Devesa JM, Devesa M, Velasco GR et al (2007) Benign rectovaginal fistulas: management and results of a personal series. Tech Coloproctol 11:128-134

150. Stolfi VM, Micossi C, Sileri P, Venza M, Gaspari A (2008) Retroperitoneal sepsis with mediastinic and subcutaneous emphysema complicating stapled transanal rectal resection. Tech Coloproctol (in press)

151. Jayne DG, Finan PJ (2005) Stapled transanal rectal resection for obstructed defaecation and evidence-based practice. Br J Surg 92:793-794

152. Pizzetti D, Annibali R, Bufo A, Pescatori M (2005) Colonic hydrotherapy for obstructed defecation. Colorectal Dis 6:107-108 (letter)

153. Pescatori M (2005) Systematic review of sacral nerve stimulation for faecal incontinence and constipation. Br J Surg 92:379 (letter)

154. Ganio E, Masin A, Ratto C et al (2001) Short-term sacral nerve stimulation for functional anorectal and urinary disturbances: results in 40 patients: evaluation of a new option for anorectal functional disorders. Dis Colon Rectum 44:1261-1267

155. Brown AJ, Anderson JH, Mckee RF, Finlay IG (2004) Surgery of occult rectal prolapse. Colorectal Dis 6:175-179

156. Scapagnini U, Guarcello V, Triolo et al (1990) Therapeutic perspectives in psychoneuroendocrinimmunology (PNEI): potential role of phosphatidylserine in neuroendocrine-immune communications. Int J Neurosci 51:299-301

157. van Dam JH, Huisman WM, Hop WCJ, Schouten WR (2000) Fecal continence after rectocele repair: a prospective study. Int J Colorectal Dis 15:54-57

158. Ayabaca SM, Zbar AP, Pescatori M (2002) Anal continence after rectocele repair. Dis Colon Rectum 45 :63-69

159. Petersen S, Hellmich G, Schuster A, Lehmann D, Albert W, Ludwig K (2006) Stapled transanal rectal resection under laparoscopic surveillance for rectocele and concomitant enterocele. Dis Colon Rectum 49:685-689 